\title{
EFFECT OF STEREOCHEMISTRY ON ESTER HYDROLYSIS BY CHOLINESTERASES: IMPLICATIONS FOR RADIOTRACER DESIGN
}

Scott E. Snyder, Xia Shao, Jacinda M. Lisi ${ }^{\dagger}$, Elizabeth R. Butch ${ }^{\dagger}$, Marc B. Skaddan and Michael R. Kilboum

Division of Nuclear Medicine, Department of Radiology, University of Michigan Medical Center, Ann Arbor, MI 48109 and Department of Chemistry, Eastern Michigan University, Ypsilanti, MI 48197.

Keywords: acetylcholinesterase, butyrylcholinesterase, carbon-11

There is currently great interest in developing radiotracers to estimate cortical acetylcholinesterase (AChE) and butyrylcholinesterase (BuChE) enzymatic activity in Alzheimer's disease patients using in vivo imaging. As part of an ongoing effort to define structure-activity relationships (SAR) for cholinesterase substrates, we have recently published in vitro and in vivo kinetic results for a series of $1-\left[{ }^{11} \mathrm{C}\right]$ methyl-4-piperidinyl esters (1). These data exhibited the expected preference of AChE for short-chain esters (acetate and propionate) and the specificity of longerchain esters (butyrate and pentanoate) for BuChE. We have also shown that this general pattern of selectivity extends to the 1-methyl-3pyrrolidinyl esters, 1a,b (2). As these latter compounds are chiral, it was of interest to extend the SAR to include the effects of stereochemistry on enzyme selectivity and cleavage rates.

Irie. et al. previously reported that the AChE-mediated cleavage rates of both the acetate and propionate esters of (R)-1-methyl-3-piperidinol were much more rapid than those of the corresponding (S)-enantiomers (3). Beckett et al. have reported a similar relationship for the stereoisomers of $\alpha$ - and $\beta$-methylcholine esters $(4,5)$. In our initial study, racemic mixtures of $1 \mathbf{a}$ and $\mathbf{1 b}$ exhibited in vitro $\mathrm{AChE}$-mediated cleavage rates similar to the corresponding 4-piperidinyl esters, but the individual enantiomers were not tested (2).

To more clearly define the structure-activity relationships for AChE and BuChE with respect to stereochemistry $\alpha$ to the ester functionality, we have prepared enantiomerically pure (R)-1-methyl-3-pyrrolidinyl propionate, $1 \mathrm{a}$ and butyrate, $1 \mathrm{~b}$, using the methods previously described for 1-methyl-4-piperidinyl propionate, PMP (6). Relative rates of substrate cleavage by purified enzymes (AChE or BuChE) were determined using a simple in vitro spectrophotometric assay (1). Esters $1 \mathrm{a}$ and $\mathbf{1 b}$ were also labeled with carbon-11, using methods similar to those reported for [ ${ }^{11} \mathrm{C}$ ]PMP (6), and the in vivo biodistribution for each in $\mathrm{CD}-1$ mice was determined.

Based on the work of Beckett et al. $(4,5)$, it would be expected that a chiral center $\beta$ to the ester functionality would also influence enzymemediated cleavage rates. To address this question we have also prepared 
chiral esters of (S)-1-methyl-2-pyrrolidinemethanol, 2a-c, and ( \pm )-1methyl-2-piperidinemethanol, 3a-c. In vitro and in vivo investigations similar to those described above are currently underway.<smiles>[R]C(=O)OC1CCN(C)CC1</smiles>

ANIP, MP4A $\mathrm{R}=\mathrm{CH}_{3}$ PMP $\mathrm{R}=\mathrm{CH}_{2} \mathrm{CH}_{3}$ nBNIP R $=\mathrm{CH}_{2} \mathrm{CH}_{2} \mathrm{CH}_{3}$<smiles>[R]C(=O)OC[C@@H]1CCCN1C</smiles>

2a $\mathrm{R}=\mathrm{CH}_{3}$

2b $\mathrm{R}=\mathrm{CH}_{2} \mathrm{CH}_{3}$

2c $\mathrm{R}=\mathrm{CH}_{2} \mathrm{CH}_{2} \mathrm{CH}_{3}$<smiles>[R]C(=O)O[C@H]1CCN(C)C1</smiles>

1a $\mathrm{R}=\mathrm{CH}_{2} \mathrm{CH}_{3}$ Ib $\mathrm{R}=\mathrm{CH}_{2} \mathrm{CH}_{2} \mathrm{CH}_{3}$<smiles>[R]C(=O)OC[C]1CCCCN1C</smiles>

3a $\mathrm{R}=\mathrm{CH}_{3}$ 3b $\mathrm{R}=\mathrm{CH}_{2} \mathrm{CH}_{3}$ 3c $\mathrm{R}=\mathrm{CH}_{2} \mathrm{CH}_{2} \mathrm{CH}_{3}$

The preliminary in vitro spectrophotometric data for these investigations is given in Table 1. (R)-1-methyl-3-pyrrolidinyl propionate, (R)1a, is cleaved by AChE nearly three times faster than both racemic $( \pm) 1 \mathrm{a}$ and PMP (Table 1), implying that the (S)-enantiomer of 1a may act as a weak AChE inhibitor. A much less dramatic stereochemical preference was observed for the BuChE-mediated cleavage of 1a. This is also consistent with the in vivo distribution in mouse brain shown in Table 2 . The retention fraction for $(R) 1$ a was higher than that for both PMP and $( \pm) \mathbf{1 a}$ in all brain areas except striatum. Similarly, the retention fractions for (R) $1 \mathrm{~b}$ were higher than those of $\mathrm{nBMP}$ in all brain areas.

The racemic primary ester $3 \mathrm{~b}$ is also cleaved by $\mathrm{AChE}$ more rapidly than is PMP. This preference for the primary ester likely arises from the shorter amine-to-carbonyl distance in $\mathbf{3 b}$, which better approximates that of acetylcholine. In contrast, (S)-1-methyl-2-pyrrolidinemethyl acetate, $2 \mathrm{a}$, is cleaved by $\mathrm{AChE}$ at a rate only 1.5 times faster than PMP and about one-third the rate of 1-methyl-4-piperidinyl acetate (AMP, MP4A). These results indicate that $A C h E$ has a preference for the (R)configuration at both the $\alpha$ - and $\beta$-positions whereas BuChE has little or no stereochemical preference. 
Table 1. Relative in vitro ChE-mediated cleavage rates. Rates are determined as a change in absorbance $(420 \mathrm{~nm})$ of m-nitrophenol per minute per unit of enzyme using the indicated substrates and purified $\mathrm{AChE}$ or $\mathrm{BuChE}$. Data are expressed relative to $\mathrm{PMP}=100$ for $\mathrm{AChE}$ and $\mathrm{nBMP}=100$ for $\mathrm{BuChE}$.

\begin{tabular}{|l|c|c|}
\multicolumn{1}{l}{ Substrate } & \multicolumn{1}{c}{$\begin{array}{c}\text { AChE } \\
\text { (rate relative to PMP) }\end{array}$} & $\begin{array}{c}\text { BuChE } \\
\text { (rate relative to nBMP) }\end{array}$ \\
\hline AMP,MP4A & $100 \pm 0.5$ & $33 \pm 1$ \\
\hline PMP & $20 \pm 0.3$ & $115 \pm 2$ \\
\hline$( \pm) 1 \mathrm{a}$ & $17.2 \pm 0.3$ & $76 \pm 13$ \\
\hline$(\mathrm{R}) 1 \mathrm{a}$ & $52 \pm 1$ & $115 \pm 8$ \\
\hline$(\mathrm{S}) 2 \mathrm{a}$ & $32 \pm 1.5$ & n.d. \\
\hline$( \pm) 3 \mathrm{~b}$ & $81 \pm 1.5$ & n.d. \\
\hline$n$ BMP & 0.00 & $100 \pm 3$ \\
\hline$( \pm) 1 \mathrm{~b}$ & 0.00 & $144 \pm 22$ \\
\hline
\end{tabular}

Table 2. Retention fractions calculated from in vivo regional distribution in mouse brain at $30 \mathrm{~min}$. post-injection relative to initial uptake at $1 \mathrm{~min}$. post-injection. Values for PMP and $(R) 1 \mathrm{a}$ are an average of 3 experiments $(n=12$ total animals per time point), $n \mathrm{BMP}$ and $\mathbf{1 b}$ are an average of 2 experiments $(\mathrm{n}=8)$ and $( \pm)$ la values are from a single study $(n=4)$.

Substrate
\begin{tabular}{|l|c|c|c|c|c|}
\hline PMP & striatum & \multicolumn{1}{c}{ cortex } & \multicolumn{1}{c}{ cerebellum } & \multicolumn{1}{c}{ hippocampus } & thalamus \\
\hline$( \pm) 1 \mathrm{a}$ & $0.71 \pm 0.05$ & $0.41 \pm 0.03$ & $0.26 \pm 0.01$ & $0.41 \pm 0.03$ & $0.36 \pm 0.10$ \\
\hline$(R) 1 \mathrm{a}$ & $0.54 \pm 0.07$ & $0.40 \pm 0.05$ & $0.31 \pm 0.05$ & $0.41 \pm 0.05$ & $0.39 \pm 0.03$ \\
\hline$n \mathrm{BMP}$ & $0.11 \pm 0.03$ & $0.08 \pm 0.02$ & $0.10 \pm 0.02$ & $0.10 \pm 0.02$ & $0.12 \pm 0.04$ \\
\hline$(R) 1 \mathrm{~b}$ & $0.20 \pm 0.04$ & $0.15 \pm 0.02$ & $0.18 \pm 0.03$ & $0.18 \pm 0.03$ & $0.23 \pm 0.03$ \\
\hline
\end{tabular}

References

1) Snyder SE et al. J Cereb Blood Flow Metab 21:132-143 (2001).

2) Bryan TA et al. J Labelled Cmpds Radiopharm 42:S207-S209 (1999).

3) Irie $\mathrm{T}$ et al. J Labeled Cmpds Radiopharm 37:214-216 (1995).

4) Beckett AH et al. J Pharm Pharmacol 15:362-371 (1963).

5) Beckett AH et al. Biochem Pharmacol 17:1601-1607 (1968).

6) Snyder SE et al. Nucl Med Biol 25:751-754 (1998).

Acknowledgements. The authors wish to acknowledge the financial support of NIH grant T32-CA09015 (to X.S.) and DOE grant DE-FG0287ER60561. Special thanks to Phil Sherman, Kyle Kuszpit and Leslie Doherty for assistance in the animal experiments. 